Agriculture, Agribusiness and Biotechnology

Vol.59: e16160223, January-December 2016 http://dx.doi.org/10.1590/1678-4324-2016160223 ISSN 1678-4324 Online Edition

\title{
Chemical Composition and Antioxidant Activity of Essential Oil and Organic Extracts of Premna integrifolia Linn
}

\author{
Sharif M. Al-Reza ${ }^{1 *}$; M. Rokonuzzaman'; Monira Afroz'; Md. Iqbal Hussain ${ }^{1}$; M. A. \\ Rashid $^{1}$; Atiqur Rahman ${ }^{1 *}$. \\ ${ }^{1}$ Islamic University, Kushtia, Bangladesh, Applied Chemistry \& Chemical Technology, Kushtia, Bangladesh .
}

\begin{abstract}
This study was designed to examine the chemical composition and in vitro antioxidant activity of the hydrodistillated essential oil and various extracts obtained from Premna integrifolia Linn. GC-MS analysis of the essential oil was resulted in determination 29 different compounds, representing $95.73 \%$ of total oil. Antioxidant activities of the essential oil and organic extracts of chloroform, ethyl acetate and methanol were determined by three different test systems namely DPPH (2,2-diphenyl-1-picrylhydrazyl), superoxide and nitric oxide radical scavenging assays. The essential oil and methanol extract showed potent antioxidant activity among all the tested samples. Furthermore, the amount of total phenolic compounds was determined and its content in methanol extract was the highest as compared to other samples. The results indicate that the essential oil and extracts of Premna integrifolia could serve as an important bio-resource of antioxidants for using in the pharmaceutical industries.
\end{abstract}

Key words: Premna integrifolia Linn, Antioxidant activity, Essential oil, Total phenolics

\footnotetext{
${ }^{1}$ Authors for correspondence: sharif@acct.iu.ac.bd \& marahman12@yahoo.com
} 


\section{INTRODUCTION}

Oxidation is essential to many living organisms for the production of energy to fuel biological processes. However, oxygen-centered free radicals and other reactive oxygen species (ROS), which are continuously, produced in vivo, result in cell death and tissue damage. The role of oxygen radicals has been implicated in several diseases, including cancer, diabetes and cardiovascular diseases, ageing, etc. $\left.{ }^{1}\right]$. Antioxidants are vital substances having the ability to protect the body from damage caused by free radical induced oxidative stress. Synthetic antioxidants, such as butylated hydroxyanisole (BHA) and butylated hydroxytoluene (BHT), have restricted to use in foods as they are suspected to be carcinogenic $\left[{ }^{2}\right]$. Therefore, the importance of searching natural antioxidants has greatly increased in recent years $\left[{ }^{3,4}\right]$. The pharmaceutical industry is undertaking the rapid development and use of natural antioxidants, especially those of plant origin, to replace synthetic drug. Moreover, essential oils are plant secondary metabolites, mainly monoterpenes, sesquiterpenes and their corresponding oxygenated derivatives, which have been showed various pharmacological effects, such as antimicrobial, antioxidant, spasmolytic, carminative, hepatoprotective, antiviral and anticarcinogenic effects $\left.{ }^{5,6}\right]$.

Although it remains unclear which of the compounds, of medicinal plants are the active ones, phenolics recently have received increasing attention because of some interesting new findings regarding their biological activities $\left[{ }^{7}\right]$. From pharmacological and therapeutic points of view, the antioxidant properties of phenolics, such as free radical scavenging and inhibition of lipid peroxidation, are the most crucial. Even though a variety of herbs and plants are known to be the sources of phenolic compounds, studies isolating phenolics and evaluating their antioxidative effects have rarely been carried out $\left.{ }^{7,8}\right]$.

Premna integrifolia Linn. (Lamiaceae) is a garden shrub, 40 species of this genus are widely naturalized in tropical and subtropical regions throughout the world, including Australia, China and the United States, India and Bangladesh. In Bangladesh, it is found mostly in Chittagong and Sunderbans. It is also been seen cultivated in home yards and gardens. In the ayurvedic system of medicine, $P$. integrifolia is known as Ganikarica while its conventional name is Ganiari. There are many species belonging to this genus but only two species namely $P$. latifolia and $P$. integrifolia were recorded as medicinal species. $P$. latifolia is grown as a large tree but $P$. Integrifolia is comparatively smaller known as shrub i.e., a woody plant smaller than a tree with branches lower than the ground and it is generally grown to 5-6 m tall. Normally most species of Premna especially P. integrifolia is used for the remedies of different ailments as in the traditional system in the indigenous part of the country. The plant is very effective in reducing blood cholesterol $\left.{ }^{9}\right]$. The leaf and bark of this plant are used for the treatment of jaundice. It is also used for the correction of menstrual problems. It is very effective for the treatment of kidney disease, liver problems and constipation $\left[{ }^{10}\right]$. In this present study, we reported antioxidant potential of essential oil and various organic extracts of this useful medicinal plant.

\section{MATERIAL AND METHODS}

\section{Chemicals and reagents list}

DPPH (2,2-diphenyl-1-picrylhydrazyl), xanthine oxidase (XOD), sodium nitroprusside, FolinCiocalteu reagent, L-ascorbic acid and kojic acid were purchased from Sigma-Aldrich, St. Louis, MO. Solvents (analytical grade) for extraction were obtained from commercial sources (SigmaAldrich, St. Louis, MO, USA).

\section{Plant Material}

The leaves of $P$. integrifolia were collected from the Boro Parulia, Gopalgonj; Arappur, Jhenaidah and Ambaria, Kushtia of Bangladesh, in May 2015 and identified by Dr. Oliur Rahman, Bangladesh National Herbarium, Dhaka, where a voucher specimen (DACB 35170) has been deposited.

\section{Isolation of Essential Oil}

The air-dried powdered leaves $(250 \mathrm{~g})$ of $P$. integrifolia were subjected to hydrodistillation for $3 \mathrm{~h}$ using a Clevenger type apparatus. The oil was dried over anhydrous $\mathrm{Na}_{2} \mathrm{SO}_{4}$ and preserved in a sealed vial at $4^{\circ} \mathrm{C}$ until further analysis.

\section{Preparation of Organic Extracts}

The air-dried leaves $(50 \mathrm{~g})$ of $P$. integrifolia were extracted with hexane, chloroform, ethyl acetate and methanol separately at room temperature for 7 days and the solvents were evaporated by vacuum rotary evaporator. The extraction process yielded in hexane $(6.0 \mathrm{~g})$, chloroform $(5.8 \mathrm{~g})$, ethyl acetate $(7.0 \mathrm{~g})$ and methanol $(6.8 \mathrm{~g})$ extracts. 
Gas Chromatography-Mass Spectrometry (GCMS) Analysis

The GC-MS analysis of the essential oil was performed using a GC-MS (Model QP 2010, Shimadzu, Japan) equipped with a ZB-1 MS fused silica capillary column $(30 \mathrm{~m} \times 0.25$ i.d., film thickness $0.25 \mu \mathrm{m})$. For GC-MS detection, an electron ionization system with ionization energy of $70 \mathrm{eV}$ was used. Helium gas was used as a carrier gas at a constant flow rate of $1 \mathrm{ml} / \mathrm{min}$. Injector and mass transfer line temperature were set at 220 and $290{ }^{\circ} \mathrm{C}$, respectively. The oven temperature was programmed from 50 to $150{ }^{\circ} \mathrm{C}$ at $3{ }^{\circ} \mathrm{C} / \mathrm{min}$, then held isothermal for $10 \mathrm{~min}$ and finally raised to 250 ${ }^{\circ} \mathrm{C}$ at $10^{\circ} \mathrm{C} / \mathrm{min}$. Diluted samples $(1 / 100, \mathrm{v} / \mathrm{v}$, in methanol) of $1 \mu \mathrm{l}$ was manually injected in the split less mode. The relative percentage of the oil constituents was expressed as percentage by peak area normalization.

Identification of components of the essential oil was based on their retention indices, relative to a homologous series of $n$-alkane $\left(\mathrm{C}_{8}-\mathrm{C}_{20}\right)$ on the ZB1 capillary column under the same operating conditions and computer matching with the Wiley 6.0 libraries, as well as by comparison of the fragmentation patterns of the mass spectra with those reported in the literature data $\left[{ }^{11}\right]$.

\section{Antioxidant Activity DPPH Assay}

DPPH radical scavenging activity of the oil and extracts was measured on the basis of the scavenging activities of the stable 2,2-diphenyl-1picrylhydrazyl (DPPH, Sigma-Aldrich, St. Louis, MO) free radical $\left[{ }^{12}\right]$. Various concentrations of test extracts $(0.1 \mathrm{ml})$ were added to $2.9 \mathrm{ml}$ of a $0.004 \%$ (w/v) methanol solution of DPPH. After $30 \mathrm{~min}$ of incubation period at room temperature, the absorbance was measured against a blank at 517 $\mathrm{nm}$. Inhibition free radical DPPH in percent $(I \%)$ was calculated in following way:

$I \%=\left(A_{\text {blank }}-A_{\text {sample }} / A_{\text {blank }}\right) \times 100$

where $A_{\text {blank }}$ is the absorbance of the control reaction (containing all reagents except the test compound), and $A_{\text {sample }}$ is the absorbance of the test compound. $\mathrm{IC}_{50}$ values (concentration of sample required to scavenge $50 \%$ of free radicals) were calculated from the regression equation. L-ascorbic acid was used as reference positive controls and all tests were carried out in triplicate.

\section{Superoxide Anion $\left(\mathrm{O}_{2}^{-}\right)$Scavenging Activity}

Superoxide radicals were generated in vitro by the xanthine oxidase (XOD). The scavenging activity of the sample was determined using the nitro-blue tetrazolium (NBT) reduction method. In this method, $\mathrm{O}_{2}$ reduces the yellow dye $\left(\mathrm{NBT}^{2+}\right)$ to produce the blue formazan, which was measured spectrophotometrically at $560 \mathrm{~nm}$. Antioxidants are able to inhibit the blue NBT formation $\left[{ }^{13}\right]$. The results were calculated as the percentage of inhibition according to the following formula:

$\mathrm{I}(\%)=100[1-(\mathrm{S}-\mathrm{SB}) /(\mathrm{C}-\mathrm{CB})]$

Where S, SB, C, and CB are the absorbance of the sample, the blank sample, the control, and the blank control, respectively.

Nitric Oxide Radical Scavenging Activity Assay The nitric oxide scavenging activity was conducted based on the method as described by Rai et al. 2006 $\left[{ }^{14]}\right.$. For the experiment, $0.5 \mathrm{ml}$ sodium nitroprusside (10 $\mathrm{mM}$, final concentration), in phosphate-buffered saline ( $\mathrm{pH} 7.4$ ), was mixed with different concentrations of $0.5 \mathrm{ml}$ sample and incubated in the dark at room temperature for 150 min. The control was run as above but the sample was replaced with the same amount of water. After the incubation period, $1.0 \mathrm{ml}$ of Griess reagent $(1 \%$ sulfanilamide, $2 \% \mathrm{H}_{3} \mathrm{PO}_{4}$ and $0.1 \% \mathrm{~N}$-(1-naphthyl) ethylenediamine dihydrochloride in distilled water) was added. Kojic acid was used as a reference standard. The absorbance of these solutions was measured at $540 \mathrm{~nm}$ against the corresponding blank solutions and referred to the absorbance of standard solutions of sodium nitrite treated in same way with Griess reagent. The $\mathrm{IC}_{50}$ value is the concentration of sample required to inhibit $50 \%$ of the NO radicals.

NO scavenged $(\%)=\left[\mathrm{Abs}_{(\text {control })}-\mathrm{Abs}\right.$ (sample) $/ \mathrm{Abs}$ (control) $] \times 100$.

Where, Abs (control): Absorbance of the control reaction and

Abs (sample): Absorbance of the sample/standard.

\section{Assay for Total Phenolics}

Total phenolic contents of the plant extract and the oil were determined by Folin-Ciocalteu reagent in alkaline medium $\left[{ }^{15}\right]$ using gallic acid as a standard. An aliquot $(0.2 \mathrm{ml})$ of the oil or the extract solution was added to a volumetric flask. Then, $46 \mathrm{ml}$ distilled water and $1 \mathrm{ml}$ Folin-Ciocalteu reagent was added, and the flask was shaken thoroughly. After 3 min, a $3 \mathrm{ml}$ solution of $\mathrm{Na}_{2} \mathrm{CO}_{3}(7.5 \%)$ was added, and the mixture was allowed to stand for $2 \mathrm{~h}$ 
with intermittent shaking. Absorbance was measured at $760 \mathrm{~nm}$ on a UV-VIS 755B spectrophotometer (Shanghai, China). The results were expressed as milligrams of gallic acid equivalents (GAEs) per gram of extract.

\section{Statistical Analysis}

The essential oil and different organic extracts were assayed for their antioxidant activities. Each experiment was run in triplicate, and mean values were calculated.

\section{RESULTS AND DISCUSSION}

The hydrodistillation of dried $P$. integrifolia gave yellowish essential oil (yields $\sim 0.8 \%$, w/w). Different compounds, representing $95.73 \%$ of the total oil from leaves. The identified compounds are listed in Table 1, according to their elution order on a VF-5 capillary column. The oil contains a complex mixture consisting of mainly oxygenated mono- and sesquiterpenes, and mono- and sesquiterpene hydrocarbons. The major compounds detected in the leaves oil were phytol $(27.25 \%)$, ahumulene $(14.21 \%)$, spathulenol $(12.12 \%), 1$ octen-3-ol (8.21\%), eugenol $(6.69 \%)$, phenylethyl alcohol $(5.81 \%)$ and caryophyllene oxide $(2.6 \%)$, as shown in Table 1. Several papers reported that all these compounds possess significant antioxidant activity in several model systems $\left.{ }^{16,17}\right]$. It is also possible that the minor components might be involved in some type of synergism with the other active compounds.

Table 1 - Chemical composition of essential oil of Premna integrifolia Linn.

\begin{tabular}{|c|c|c|c|}
\hline $\mathbf{R I}^{\mathbf{a}}$ & Compounds & $\operatorname{RA}^{b}(\%)$ & Identification $^{\mathrm{c}}$ \\
\hline 719 & Cyclohexane & 1.03 & RI, MS \\
\hline 856 & Hexan-1-ol & 0.65 & RI, MS \\
\hline 932 & $\alpha$-Pinene & 0.86 & RI, MS \\
\hline 961 & 1-Octen-3-ol & 8.21 & RI, MS \\
\hline 963 & $\beta$-Pinene & 1.11 & RI, MS \\
\hline 966 & 3-Octanol & 0.97 & RI, MS \\
\hline 1005 & 1,8-Cineole & 0.93 & RI, MS \\
\hline 1028 & cis -2-Octenal & 1.13 & RI, MS \\
\hline 1136 & Phenylethyl alcohol & 5.81 & RI, MS \\
\hline 1174 & Indole & 0.91 & RI, MS \\
\hline 1182 & Decanal & 0.87 & RI, MS \\
\hline 1200 & Dodecane & 0.49 & RI, MS \\
\hline 1366 & Damascenone & 0.18 & RI, MS \\
\hline 1380 & Eugenol & 6.69 & RI, MS \\
\hline 1386 & Azulene & 0.61 & RI, MS \\
\hline 1410 & Isoeugenol & 1.83 & RI, MS \\
\hline 1414 & $\beta$-Carryophyllene & 0.92 & RI, MS \\
\hline 1426 & Benzofuranone & 0.98 & RI, MS \\
\hline 1447 & $\alpha$-Humulene & 14.21 & RI, MS \\
\hline 1550 & Spathulenol & 12.12 & RI, MS \\
\hline 1561 & Caryophyllene oxide & 2.60 & RI, MS \\
\hline 1580 & Cubenol & 1.67 & RI, MS \\
\hline 1609 & Tetradecanal & 0.32 & RI, MS \\
\hline 1616 & Tumerone & 0.83 & RI, MS \\
\hline 1755 & Pentadecanol & 0.64 & RI, MS \\
\hline 1869 & Pentadecanoic acid & 0.23 & RI, MS \\
\hline 1968 & Hexadecanoic acid & 1.06 & RI, MS \\
\hline 2009 & Eicosane & 0.62 & RI, MS \\
\hline \multirow[t]{2}{*}{2045} & Phytol & 27.25 & RI, MS \\
\hline & Total & 95.73 & \\
\hline
\end{tabular}

a Retention indices relative to $n$-alkanes $\mathrm{C}_{8}-\mathrm{C}_{20}$ on ZB-1 capillary column. ${ }^{\mathrm{b}}$ Relative area (peak area relative to the total peak area). $\quad$ Identification: MS, comparison of mass spectra with MS libraries; RI, comparison of retention index with bibliography. 
The DPPH is a stable free radical, which has been widely accepted as a tool for estimating free radical scavenging activities of antioxidants $\left[{ }^{18}\right]$. The effect of antioxidants on DPPH radical scavenging was thought to be due to their hydrogen donating ability. $\mathrm{DPPH}^{-}$is a stable free radical and accepts an electron or hydrogen radical to become a stable diamagnetic molecule $\left[{ }^{19}\right]$. The reduction capability of DPPH radicals was determined by the decrease in its absorbance at $517 \mathrm{~nm}$ induced by antioxidants. The DPPH radical scavenging activity of the essential oil and the organic extracts are shown in Figure 1.

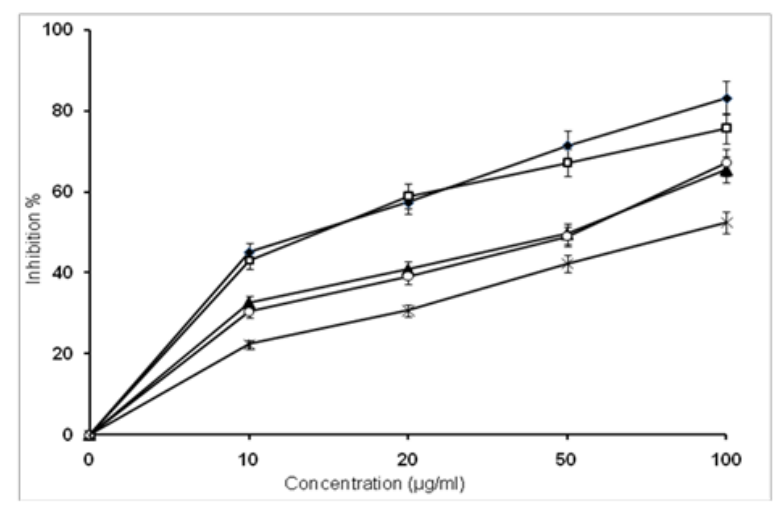

Figure 1- DPPH tadical scavenging activity of essential oil and extracts from $P$. integrifolia leaves $(\rightarrow)$, L-Ascorbic acid; ( $(-)$ ), Essential oil; $\left({ }^{-}\right), \mathrm{MeOH}$ extract, $(-\infty)$, EtOAc extract, $(*), \mathrm{CHCl}_{3}$ extract.
The scavenging effect of the essential oil and organic extracts of methanol, ethyl acetate and chloroform on DPPH radicals increased with increasing concentration and was $75.78 \%, 65.51 \%$, $67.24 \%$ and $52.48 \%$ at a concentration of 100 $\mu \mathrm{g} / \mathrm{ml}$, respectively, while ascorbic acid was the highest DPPH radical scavenging activity $(83.23 \%)$. As shown in Table 2, the essential oil had the strongest free radical-scavenging activity with an $\mathrm{IC}_{50}$ value of $24.19 \mu \mathrm{g} / \mathrm{ml}$. The methanol and ethyl acetate extract showed moderate activity with $\mathrm{IC}_{50}$ value of 33.64 and $49.38 \mu \mathrm{g} / \mathrm{ml}$, respectively, while chloroform extract showed little activity $\left(\mathrm{IC}_{50}\right.$ $=90.52 \mu \mathrm{g} / \mathrm{ml}$ ) as compared to L-ascorbic acid $\left(\mathrm{IC}_{50}=15.13 \mu \mathrm{g} / \mathrm{ml}\right)$. These results indicated that both essential oil and extracts have a noticeable effect on scavenging free radical.

Table 2 - Antioxidant $\mathrm{IC}_{50}$ values in different in vitro methods.

\begin{tabular}{lccc}
\hline Samples & DPPH assay & Superoxide anion assay & Nitric Oxide assay \\
\hline Essential oil & $24.19 \pm 1.2$ & $21.90 \pm 1.1$ & $89.75 \pm 0.9$ \\
MeOH extract & $33.64 \pm 0.6$ & $38.10 \pm 1.2$ & $159.15 \pm 1.1$ \\
EtOAc extract & $49.38 \pm 0.4$ & $69.40 \pm 0.6$ & $210.9 \pm 0.2$ \\
CHCl $_{3}$ extract & $90.52 \pm 1.2$ & nd & nd \\
L-Ascorbic acid & $15.13 \pm 0.2$ & nd & $51.85 \pm 0.6$ \\
Kojic acid & nd & $5.8 \pm 1.2$ &
\end{tabular}

In the PMS/NADH-NBT system, superoxide anion derived from dissolved oxygen by PMS/NADH coupling reaction reduces NBT. The decrease of absorbance at $560 \mathrm{~nm}$ with antioxidants thus indicates the consumption of superoxide anion in the reaction mixture. Figure 2 shows the percent inhibition of superoxide radical generation of essential oil and extracts of $P$. integrifolia leaves at different concentrations and comparison with same doses of kojic acid. The percentage inhibition of superoxide generation by $100 \mu \mathrm{g} / \mathrm{ml}$ concentration of kojic acid and essential oil was found as $91.8 \%$ and $84.80 \%$, and greater than that same doses of methanol and ethyl acetate extracts $(67.47 \%$ and 
$59.26 \%$ ), respectively. Similar results were also found in $\mathrm{IC}_{50}$ values, as shown in Table 2 . These results imply that essential oil and organic extracts of $P$. integrifolia leaves are superoxide scavengers and their capacity to scavenge superoxide may contribute to their antioxidant activity.

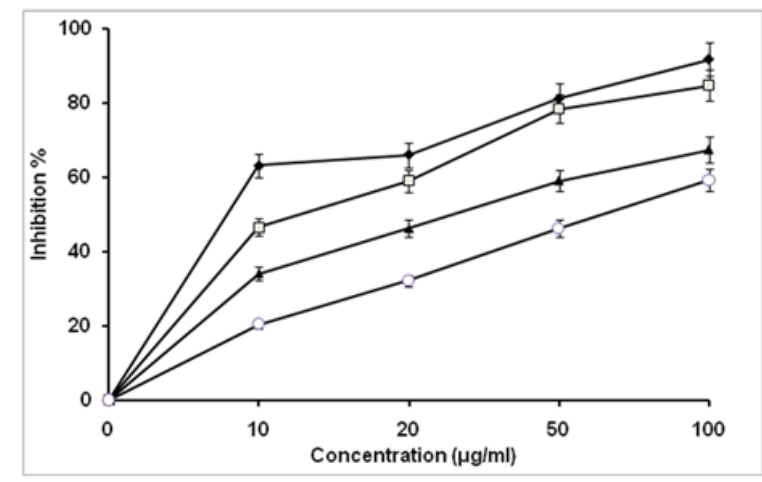

Figure 2 - Superoxide anion radical scavenging activity of essential oil and extracts from $P$. integrifolia

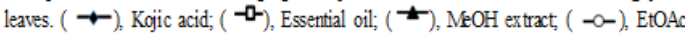
extract.

'NO has been found to play a critical role in numerous physiological processes, as well as in the pathophysiology of many human diseases. Its toxicity is not only related to the levels of $\mathrm{NO}$ generation but is also highly dependent upon the levels and types of other species which react with NO, converting it into toxic oxidants and nitrating agents. The reactivity of RNS (Reactive Nitrogen Species) may have profound effects on the biological activity of numerous molecules $\left[{ }^{20}\right]$. The plant and plant products may have the property to counteract the formation of nitric oxide radicals and in turn may be of considerable interest in preventing the ill effects of excessive nitric oxide generation in the human body. Figure 3 illustrates the percentage inhibition of nitric oxide generation by essential oil and extracts of $P$. integrifolia leaves at different concentrations and comparison with same doses of kojic acid. Percent inhibition of kojic acid and essential oil of $P$. integrifolia leaves were calculated as $60.08 \%$ and $50.42 \%$, respectively, while methanol and ethyl acetate extract showed considerably less effective NO radical scavenging activity with $34.33 \%$ and $32.18 \%$ inhibition, respectively. The $\mathrm{IC}_{50}$ values of all the tested samples are shown in Table 2. In this study, methanol extract showed potent antioxidant activity among the tested extracts which could be due to the presence of higher amount of bioactive compounds in this polar extract.

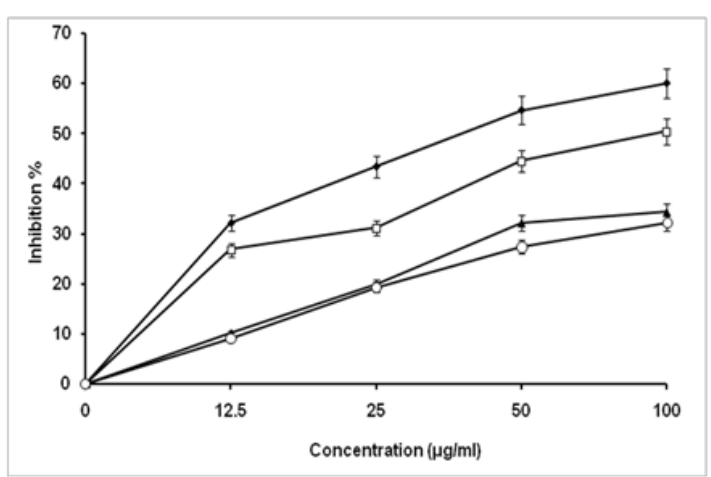

Figure 3: Nitric oxide radical scavenging activity of essential oil and extracts from $P$. integrifolia leaves. ( $(\boldsymbol{-})$, Kojic acid; $\left({ }^{-0}\right)$, Essential oil; ( $(\boldsymbol{\downarrow}), \mathrm{MeOH}$ extract; $(\infty)$, EtOAc extract

The phenolic compounds are very important plant constituents because of their scavenging ability due to their hydroxyl groups $\left[{ }^{21}\right]$. Based on the absorbance values of the essential oil and various extract solutions, reacted with Folin-Ciocalteu reagent and compared with the standard solutions of gallic acid equivalents, as described above, total phenolics are shown in Figure 4. The standard curve equation is, $\mathrm{y}=8.310 \mathrm{x}+0.036$. The amount of total phenolics in the essential oil was determined as 121 $\mathrm{GAE} \mathrm{mg} / \mathrm{g}$ sample. Among the organic extracts, the amount of total phenolics was highest in the methanol extract (124 GAE mg/g sample), followed by the relatively non-polar ethyl acetate extract (112 GAE $\mathrm{mg} / \mathrm{g}$ sample).The lowest value was exhibited by the chloroform extract ( $82 \mathrm{GAE} \mathrm{mg} / \mathrm{g}$ sample). The key role of phenolic compounds as scavengers of free radicals is emphasised in several reports $\left.{ }^{22,23}\right]$. Phenolic antioxidants are products of secondary metabolism in plants, and the antioxidant activity is mainly due to their redox properties and chemical structure, which can play an important role in chelating transitional metals, inhibiting lipoxygenase and scavenging free radicals $\left[{ }^{24}\right]$.

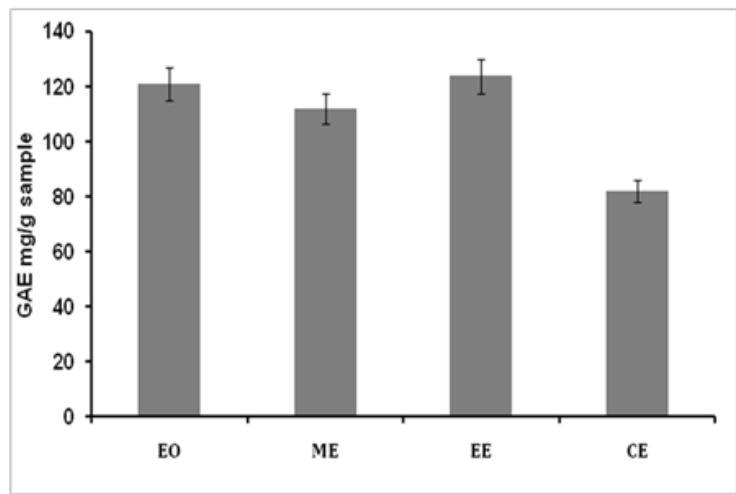

Figure 4 - The amount of total phenolics in essential oil and ex tracts of $P$. integrifolia leaves. $\mathrm{EO}$, essential oil; $\mathrm{ME}$, methanol extract; $\mathrm{EE}$, ethylacetate extract; $\mathrm{CE}$, chloroform extract. 
Therefore, it could be concluded that the phenolic compounds were highly involved in the antioxidant activity found in essential oil and organic extracts of $P$. integrifolia leaves and also able to enhance or complement their activity. The amount of phenolic compounds was comparable with the results described in the literature for other plant extracts $\left[{ }^{25,26}\right]$.

\section{CONCLUSIONS}

This study concludes that the antioxidant and radical scavenging activity of the essential oil and organic extracts of $P$. integrifolia leaves indicate towards its strong protective role against oxidative diseases and possible use of $P$. integrifolia leaves as a natural antioxidant for potential pharmaceutical application. The oil showed higher antioxidant activities than organic extracts, whereas methanol extract had potent antioxidant activity than other extracts as compared to three tested methods. Further work is needed to fully understand the variables that can affect the evaluation of the antioxidant capacity by different methodologies.

\section{ACKNOWLEDGEMENTS}

This work was carried out with support of "the ministry of science and technology, Bangladesh (Project No. 39.009.002.01.00.053.2014-2015/ID250/756)'.

\section{REFERENCES}

1- Halliwell B, Gutteridge JMC. Free radicals in biology and medicine. Oxford University Press, Oxford, USA, 1999.

2- Barlow SM. Toxicological Aspects of Antioxidants Used as Food Additives, in Food Antioxidants, Hudson B. J. F., (Ed.), Elsevier, Amsterdam, 1990. p. 23.

3- Demirtas I, Erenler R, Elmastas M, Goktasoglu A. Studies on the antioxidant potential of flavones of Allium vineale isolated from its water-soluble fraction. Food Chem. 2013; 136: 34-40.

4- Rahman A, Bajpai VK, Dung NT, Kang SC. Antibacterial and antioxidant activities of the essential oil and methanol extracts of Bidens frondosa Linn. Int J Food Sci Tech. 2011; 46:1238-1244.

5- Rahman A, Al-Reza SM, Kang SC. Antilisterial effect of essential oil and extracts of Poncirus trifoliata Rafin. Seeds. J Food Biochem. 2014; 38: 50-55.

6- Periasamy VS, Athinarayanan J, Alshatwi AA. Anticancer activity of an ultrasonic nanoemulsion formulation of Nigella sativa L. essential oil on human breast cancer cells. Ultrason Sonochem. 2016; 31: 449-455.

7- Chu Y, Chang C, Hsu H. Flavonoid content of several vegetables and their antioxidant activity. J Sci Food Agric. 2010; 80: 561-566.

8- Yang D, Xie H, Jiang Y, Wei X. Phenolics from strawberry cv. Falandi and their antioxidant and $\alpha$ glucosidase inhibitory activities. Food Chem. 2016; 194: 857-863.

9- Dey TK. Useful Plants of Bangladesh, 2nd ed. The Ad. Communication, Chittagong, 2006, p. 96.

10- Husain, Virmani OP, Popli SP, Misra LN, Gupta MM, Srivastava GN, Abraham Z, Singh AK. Dictionary of Indian Medicinal Plants. Central Institute of Medicinal and Aromatic Plants, New Delhi, 1992; p. 375 .

11- Adams RP. Identification of essential oil components by gas chromatography/ Mass Spectroscopy, $4^{\text {th }}$ Edition, Allured Publishing Corporation, Carol stream, Illinois, USA, 2007.

12- Tepe B, Daferera D, Arzuhan-Sihoglu T, Polissiou M, Sokmen A. Antioxidant activity of the essential oil and various extracts of Nepeta flavida Hub.-Mor. from Turkey. Food Chem. 2007; 103: 1358-1364.

13- Cos P, Ying LY, Calomme M, Hu JH, Cimanga K, Van PB et al. Structure-activity relationships and classification of flavonoids as inhibitors of xanthine oxidase and superoxide scavengers. J Nat Prod. 1998; 61: 71-76.

14- Rai S, Wahile A, Mukherjee K, Saha BP, Mukherjee PK. Antioxidant activity of Nelumbo nucifera (sacred lotus) seeds. J Ethnopharmacol. 2006; 104: 322-327.

15- Lister E, Wilson P. Measurement of total phenolics and ABTS assay for antioxidant activity (personal communication). Crop Research Institute, Lincoln, New Zealand, 2001.

16- Cabrera AC, Prieto JM. Application of artificial neural networks to the prediction of the antioxidant activity of essential oils in two experimental in vitro models. Food Chem. 2010; 118: 141-146.

17- Ruberto G, Baratta MT. Antioxidant activity of selected essential oil components in two lipid model systems. Food Chem. 2000; 69: 167-174.

18- Sánchez-Moreno C. Review: Methods used to evaluate the free radical scanvenging activity in foods and biological systems. Food Sci Tech Int. 2000; 8: 121-137.

19- Soares JR, Dins TCP, Cunha AP, Ameida LM. Antioxidant activity of some extracts of Thymus zygis. Free Rad Res. 1997; 26: 469-478.

20- Elserich JP, Patel RP, O'Donnell VB. Patophysiology of nitric oxide and related species: Free radical reactions and modification of biomolecules. Mol Asp Med. 1998; 19: 221-357.

21- Hatano T, Edamatsu R, Mori A, Fujita Y, Yasuhara E. Effect of interaction of tannins with co-existing substances. VI. Effects of tannins and related 
polyphenols on superoxide anion radical and on DPPH radical. Chem Pharm Bull. 1989; 37: 2016-2021.

22- Madsen HL, Nielsen BR, Bertelsen G, Skibsted LH. Screening of antioxidative activity of spices. A comparison between assays based on ESR spin trapping and electrochemical measurement of oxygen consumption. Food Chem. 1996; 57: 331-337.

23- Moller JKS, Madsen HL, Altonen T, Skibsted LH. Dittany (Origanum dictamnus) as a source of waterextractable antioxidants. Food Chem. 1999; 64: 215-219.

24- Decker EA. Phenolics: prooxidants or antioxidants? Nutr Rev. 1997; 55: 396-398.

25- Al-Reza, SM, Rahman A, Sattar MA, Rahman MO, Fida HM. Essential oil composition and antioxidant activities of Curcuma aromatica Salib. Food Chem Toxicol. 2010; 48: 1757-1760.

26- Rahman A, Kim EL, Kang SC. Antibacterial and antioxidant properties of Ailanthus altissima Swingle leave extract to reduce foodborne pathogens and spoiling bacteria. J Food Safety. 2009; 29: 499-510. 